\title{
النسج باستخدام الشرائط الجاهزة للتغلب على مشكلات تنفيذ التزاكيب النسجية للطلاب المبتدئين
}

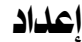 \\ د/أسماء محمد خطاب \\ مدرس النسيج بقسم التربية الفنية \\ كلية التربية النوعية ، جامعة طنطا
}

مجلة بحوث التربية النوعية ـ جامعة المنصورة

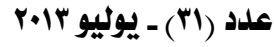




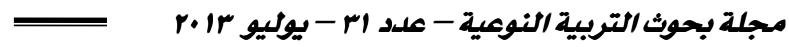

\section{النسج باستخدام الشرائط الجاهزة للتذفب على هشكلات \\ تنفيذ التزاكيب النسجية لاطلاب المبتدئين}

إعداد

" دأسماء محمد خطاب

\section{مling}

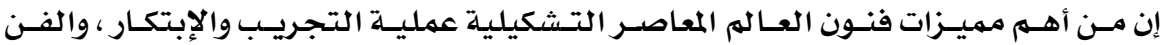

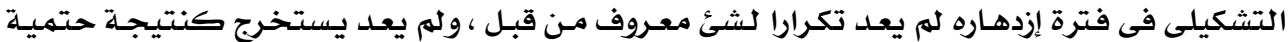

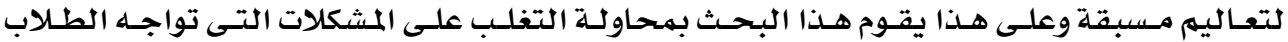

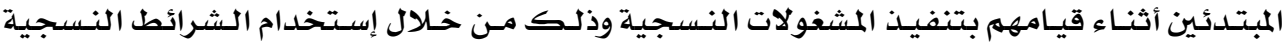

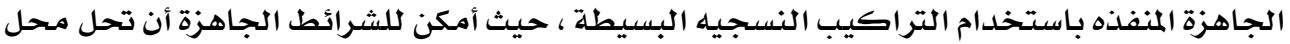

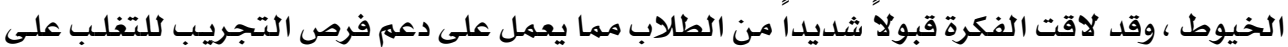

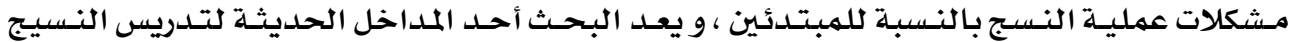

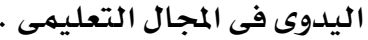


Abstract:

One of the most important characteristics of modern fine arts is the process of experimentation and innovation, and art in the prosperity no longer repeatedly to something known before, is no longer extracted as an inevitable result of the teachings of the prior and this is the search of trying to overcome the problems faced by students novices during their implementation hand textile weave through the use of strips of textile ready Implementing using simple fabric structure, where possible, to strips of textile ready Implementing to replace the fibers, has received the idea acceptable severely students, which works to support opportunities experimentation to overcome practical problems for starters, and longer search a entrances modern teaching weaving in the educational field. 
إعداد

" أسماء محمد خطاب

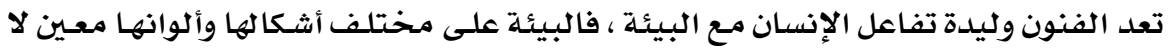

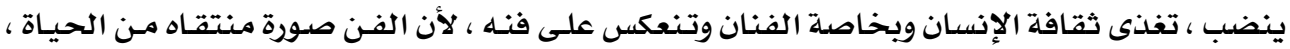

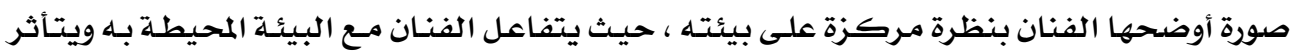

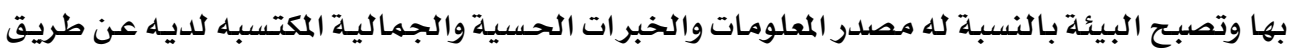

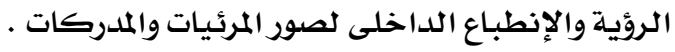

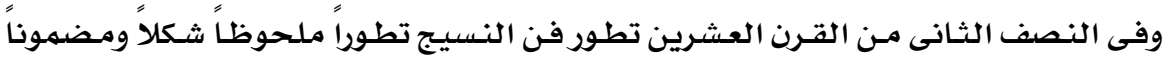

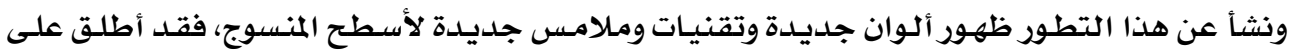

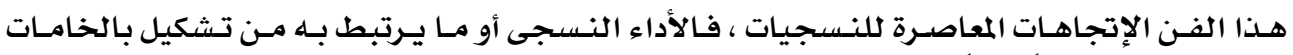

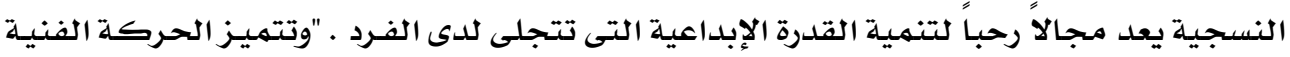

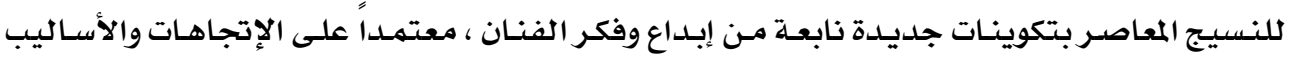

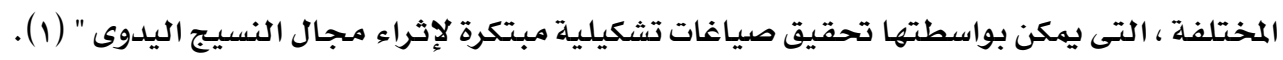

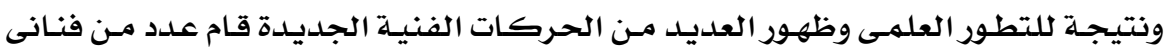

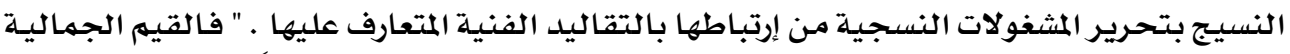

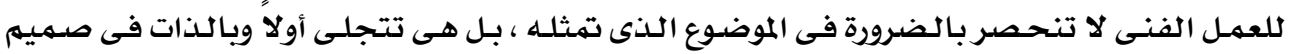

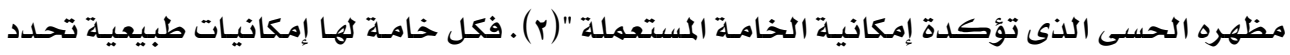

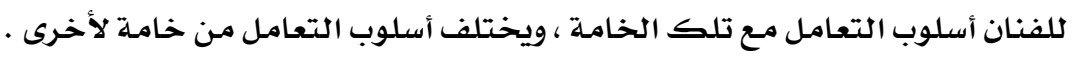

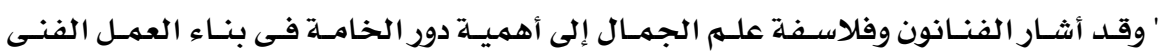

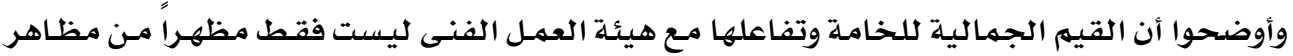

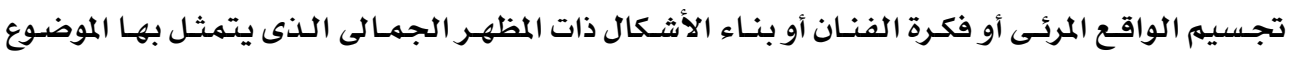

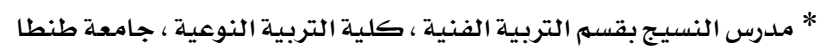

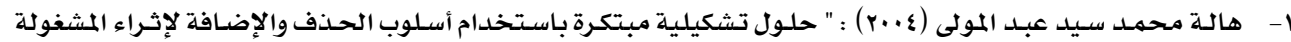

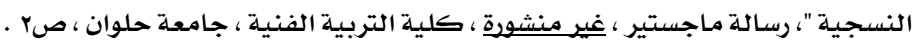

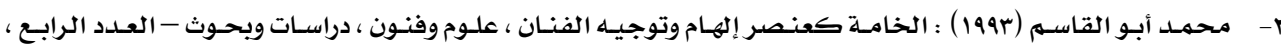




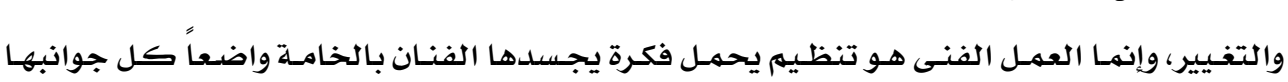
التشكيليـة فى إعتبـاره "( (1).

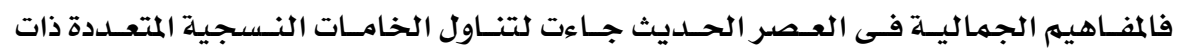

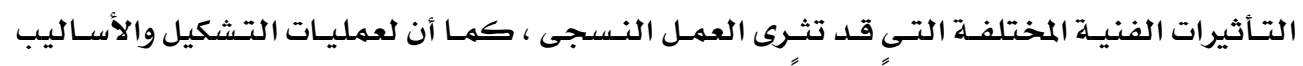

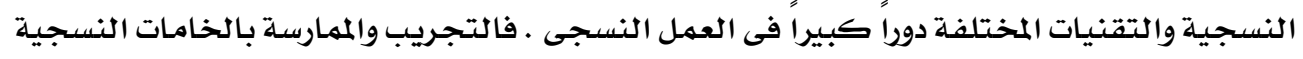
المختلفة قد " تبنى فى نفوس الطلاب القدرة على إدراك العلاقات والتشكيل بمختلف الخامـات لإيجـاد

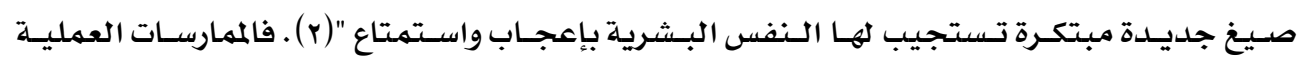
للخامـات النسجيـة تمنح الطلاب الإرتياح الشخصى كها تكسبهم خبر ات متعـددة فى كيفيـة إختيـار الخامات المناسبـة لكل عمل نسجى على حلده . " ويحاول النسـاج دائماً إضفاء نوع من الجاذبية والجهمال على مظهر ما ينتجهـ من منسوجات

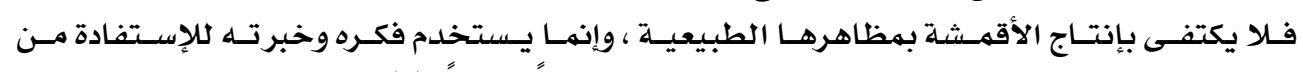
الإمكانيات المتاحة له لتحسين شكل الإنتاج وإكسـابـه مظهرا جميلاً "(r).

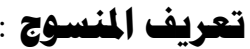

المنسوج عبـارة عن جسم مسطح يتكون عن طريق تعاشق ( تقاطع) خيوط طولية تعرف بإسهم

خيوط السلداء مـع خيوط عرضية تعرف بإسهم خيوط اللحمهة فى زاوية قائمهة ( . O(ه).

ويهكن بنـاء هذه الأقمشة فى صور وأشكال متعـددة منها البسسيط ومنهـا المعقد تبعـا لطريقة

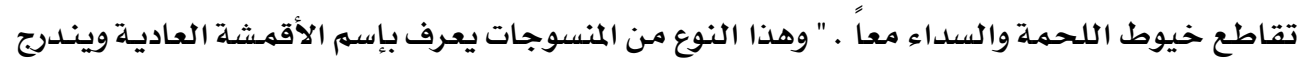
تحت هـا النـوع مـن المنسوجـات : النسيـج السـادة Plain weave والنسيـج المبردى Twill weave ،

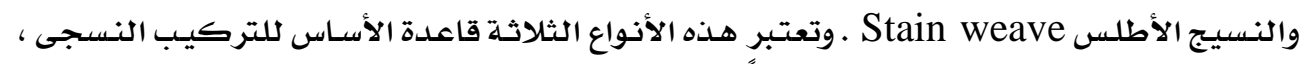

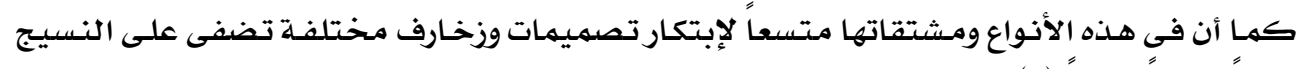

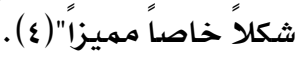

وفى دروس التربيـة الفنيـة للطـلاب المبتـدئين يـتم أولاً توقيـع التراكيـب النسسجيـة على ورق

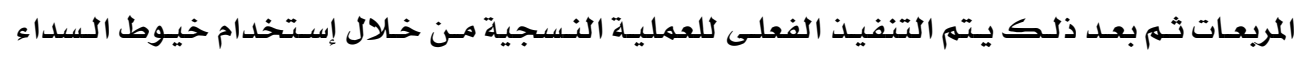
واللحمـة والنسـج بها على الأنوال البسيطة مثل نوول البرواز أو الكرتون .

" والغرض الأسـاسى مـن المربعات هو ترجمـة التركيب النسسجى المستخدم فى أسـلوب تقـاطع

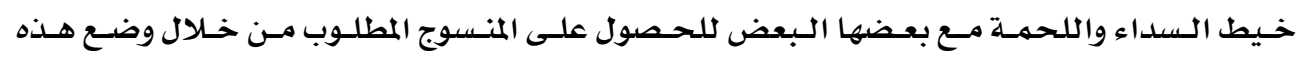

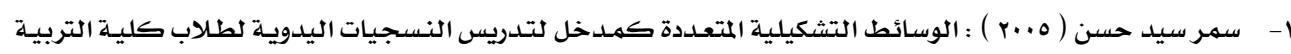

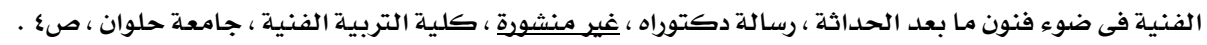

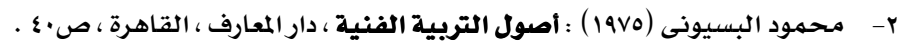

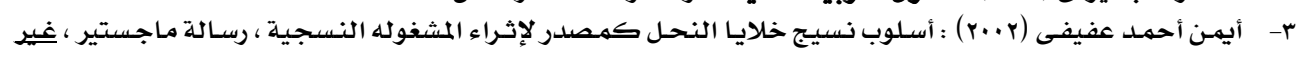

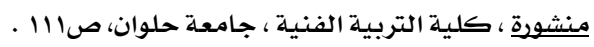

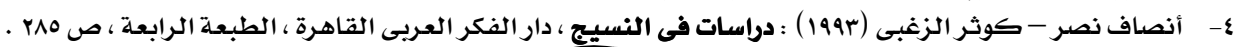


التراكيـب النسـجية بطريقـة مبسطة داخل هـذه المربعـات ـ فكل مسسافة رأسية تنـشأ بـين خطـين مـن

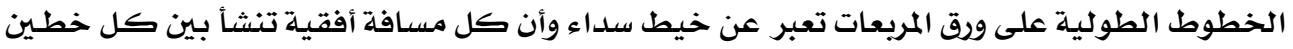

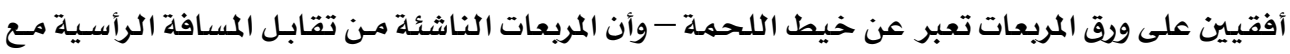

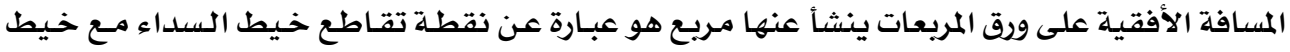

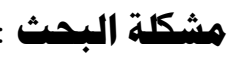

مـن خـلال قيـام الباحثـة بتـدريس مـادة النسـيـات اليدويـة بكليـة التربيـة النوعيـة - جامعسة

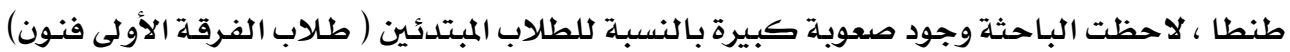

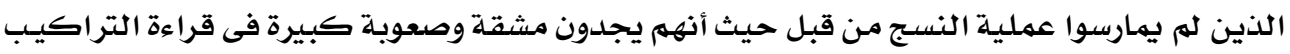

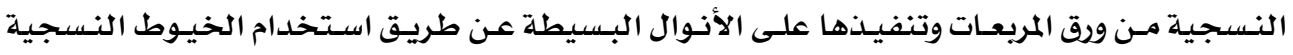

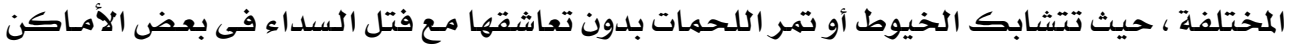

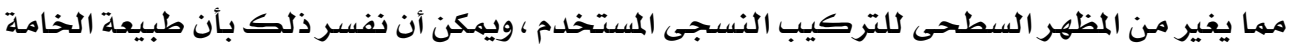

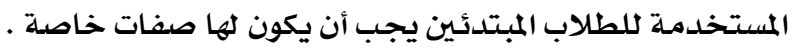

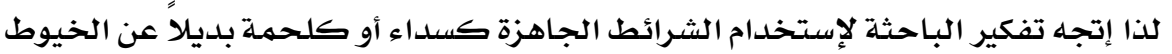

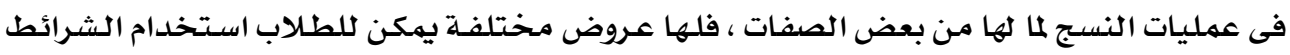

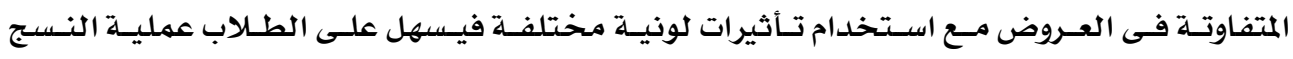

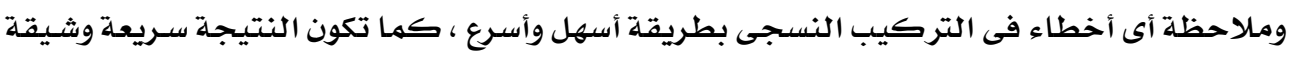

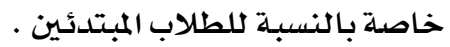
ومن هنا يمكن صياغة مشكلة البحث يِّ التساؤل التالي :-

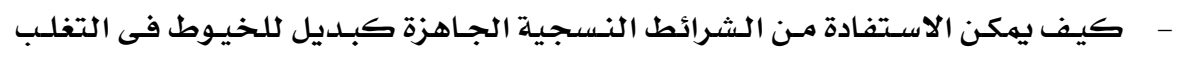

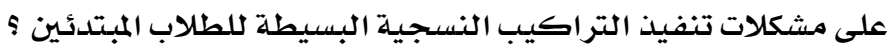

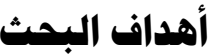

التغلب على مشكلات تنفيذ التراكيب النسجية بالخيوط بالنسبة للطلاب المبتدئين .

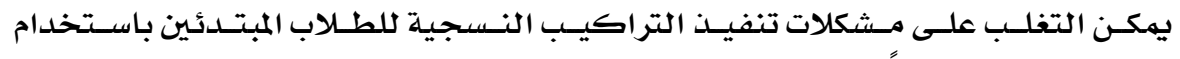

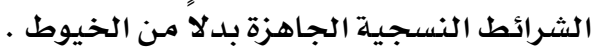

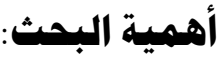

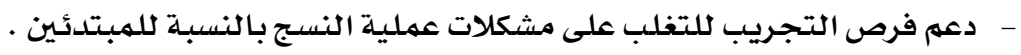

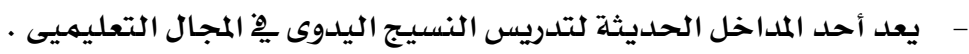

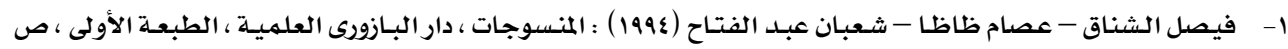




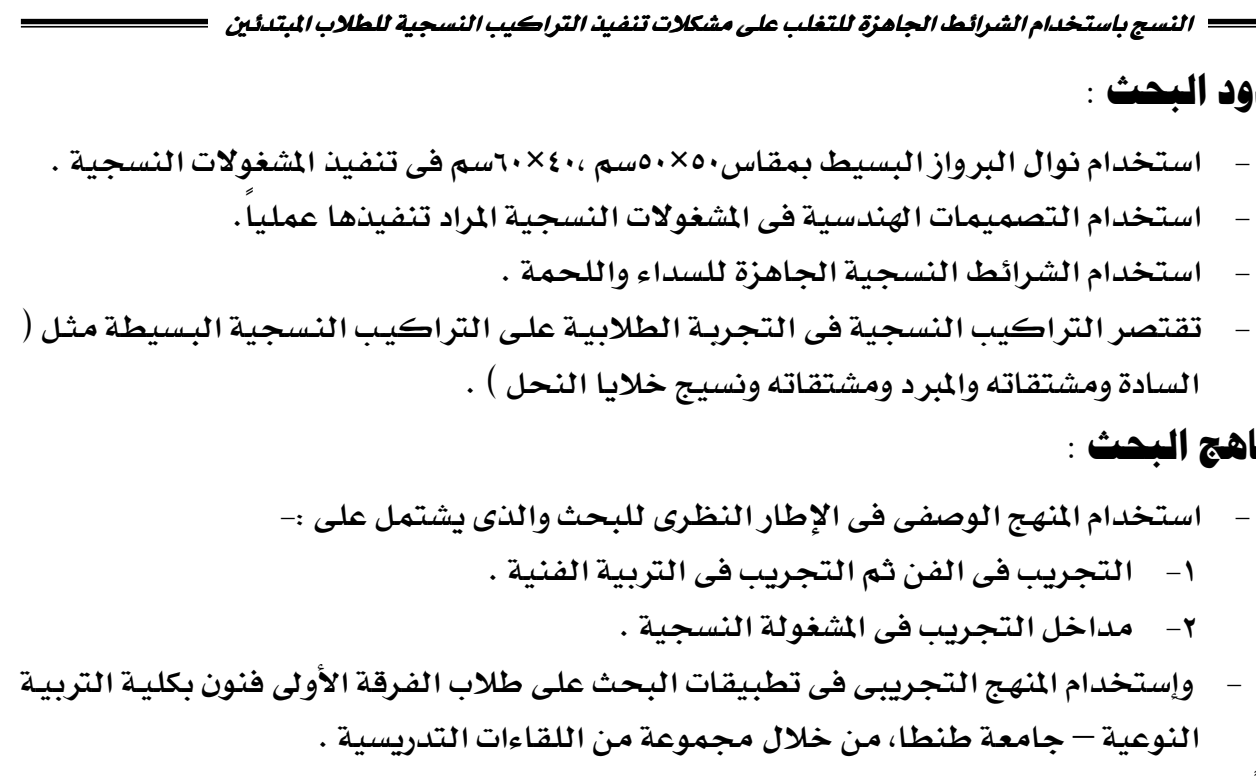

أولاً : الإطار النظرى : النجرعية

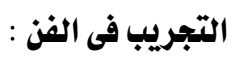

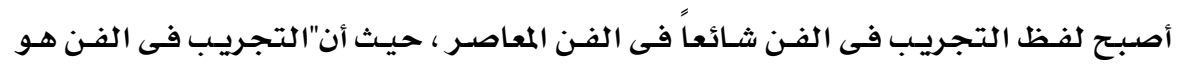

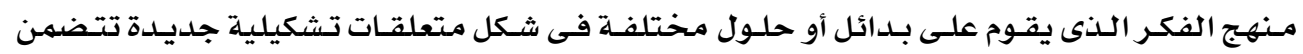

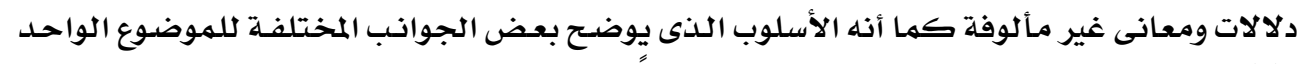

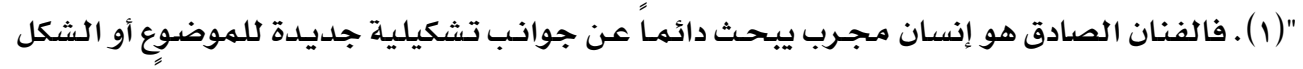

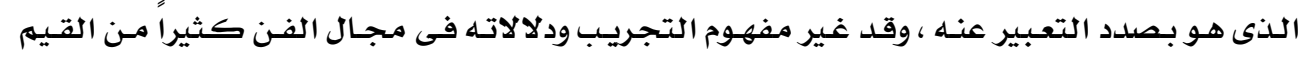

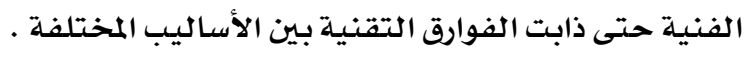

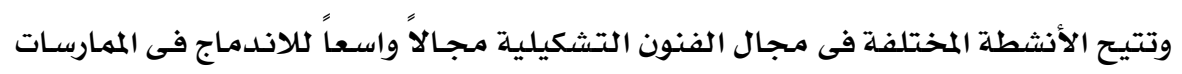

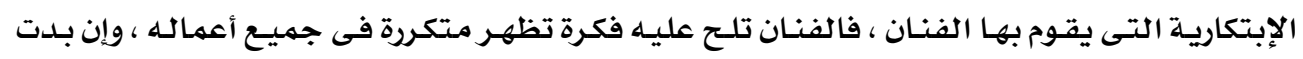

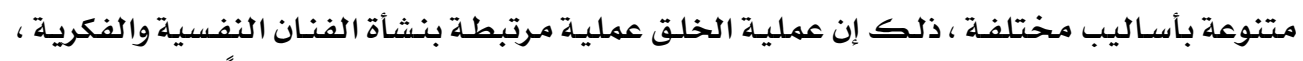

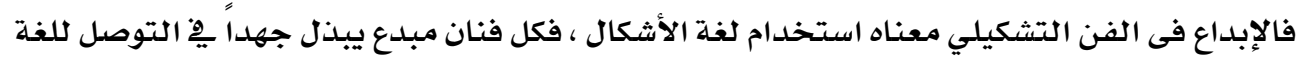

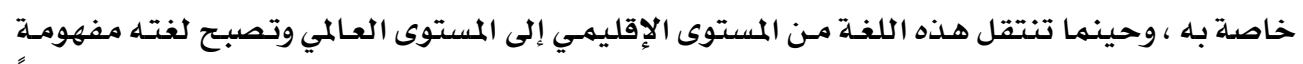

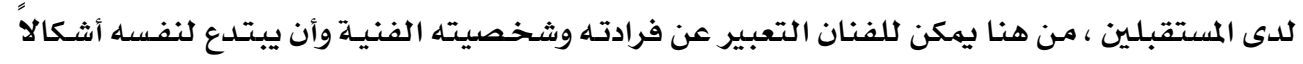

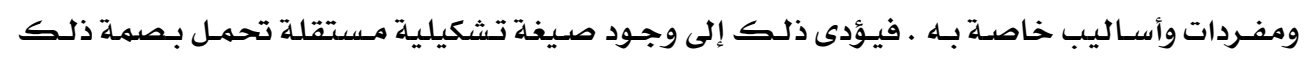
الفنان

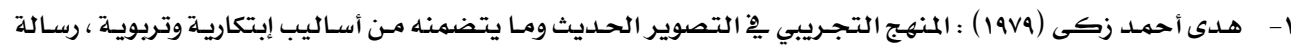

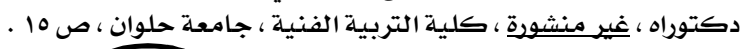


" يعد ميدان التربية الفنية من أكثر الميادين إتساعاً لممارسسة التجريبب للوصدول إلى حلـول

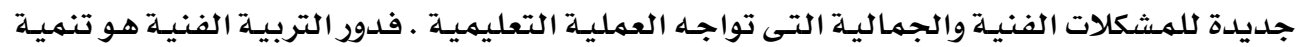

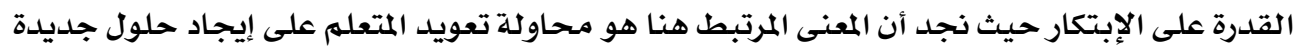

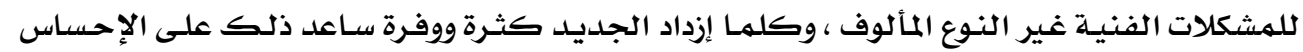

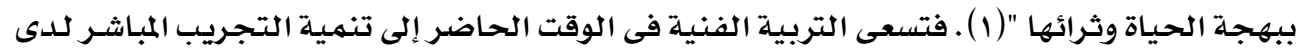

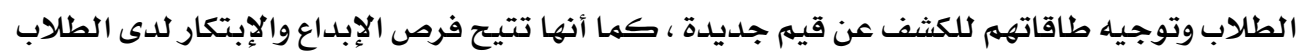

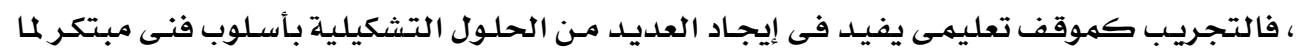
يقابل هؤلاء الطلاب من مشكلات .

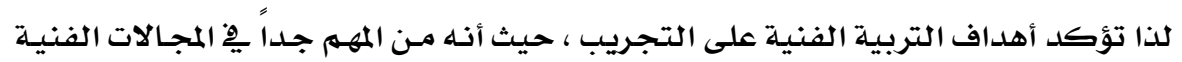

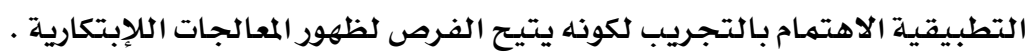

\section{مداخل التجريب فى المشفولة النسجية :}

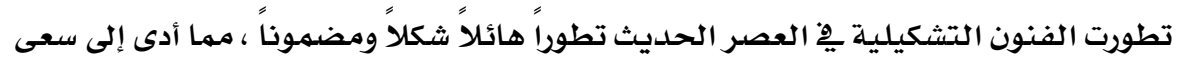

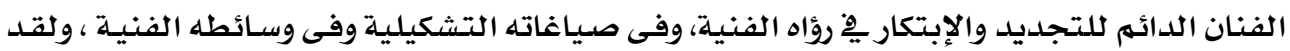

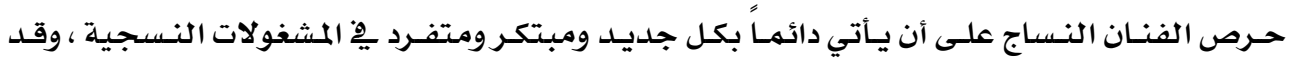

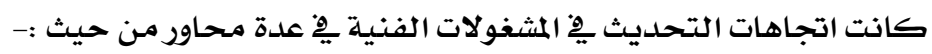

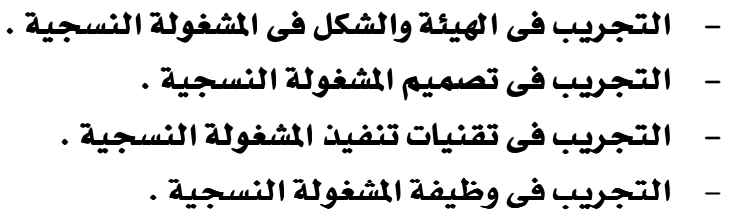

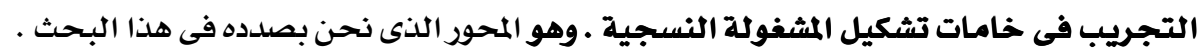

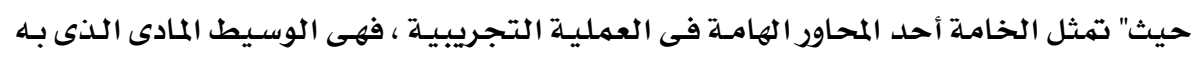

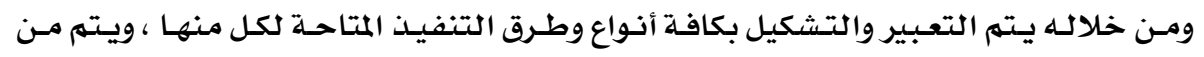

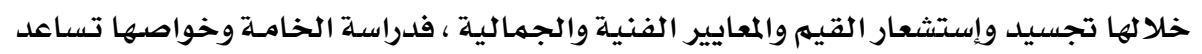

على سهولة التشكيل بها وإبراز إمكاناتها الفنية والتقنية "( ( ).

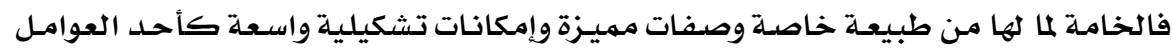

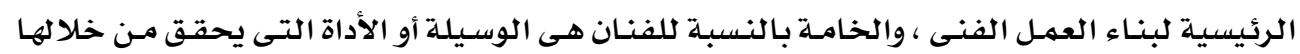

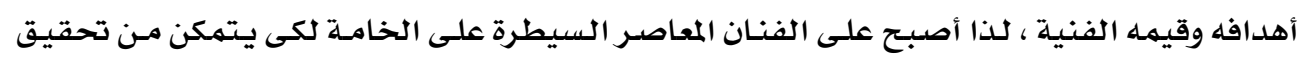

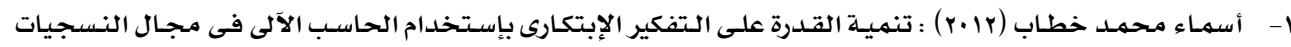

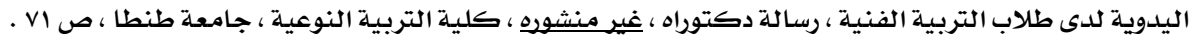

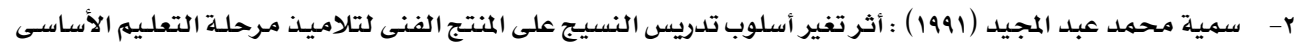

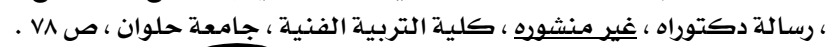




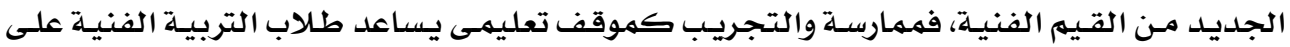

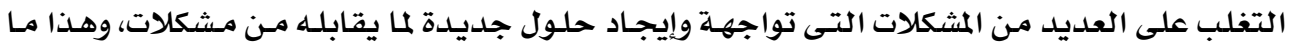

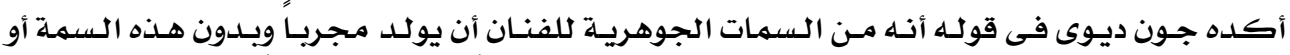

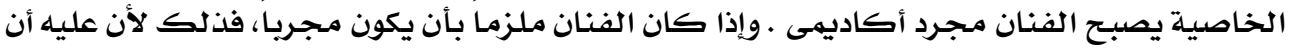
يعبر عن خبرة ذات طابع فردى عميق "( ) . ل

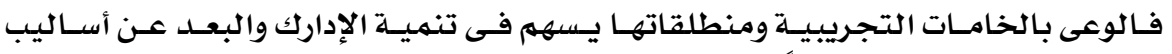

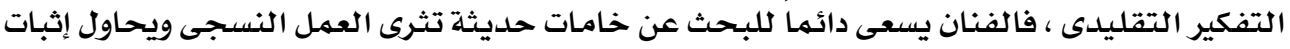

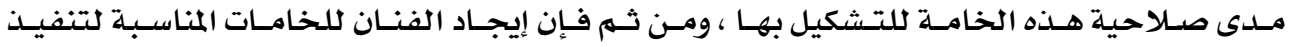

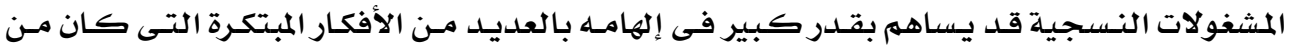

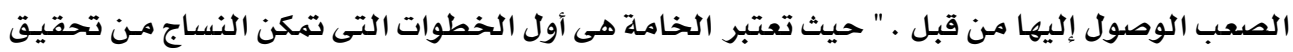

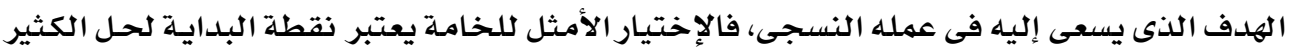

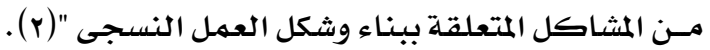

\section{ثانيًا: التبربة البحثية:}

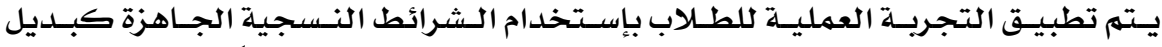

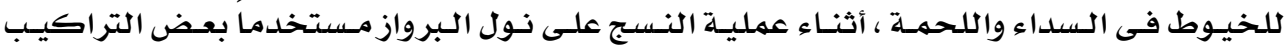

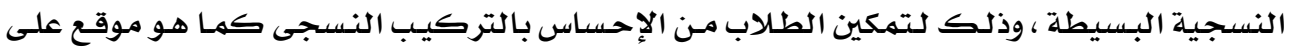

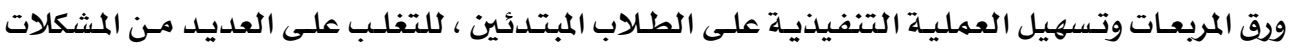

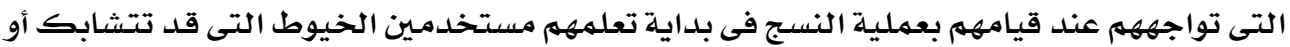

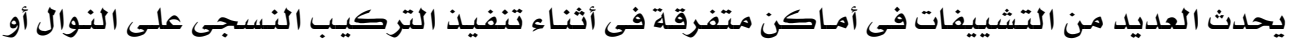

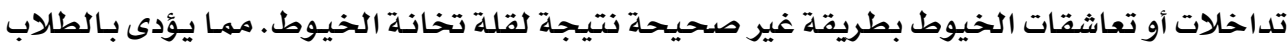

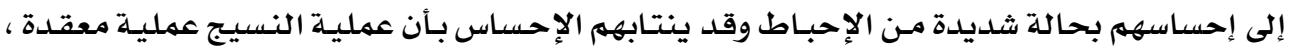

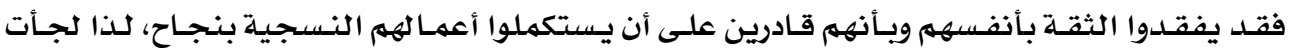

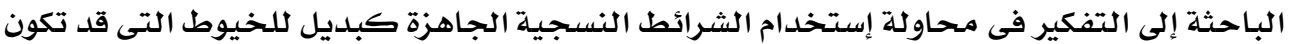

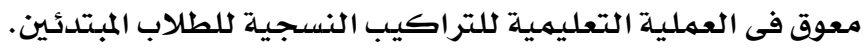
ويمكن الحصول على تأثيرات ومظاهر متنوعة لسطوح المشغولات النسجية عن طريق إحداث

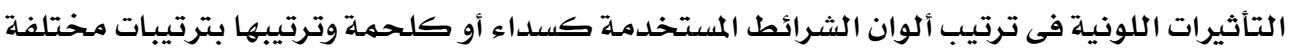

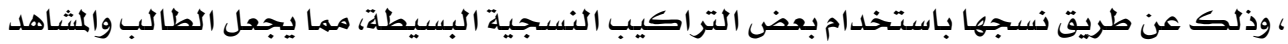

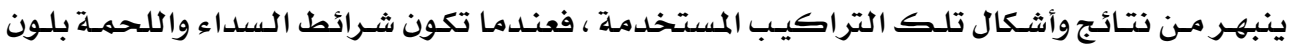

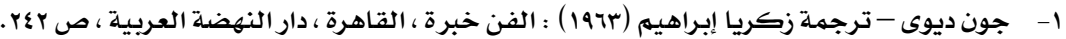

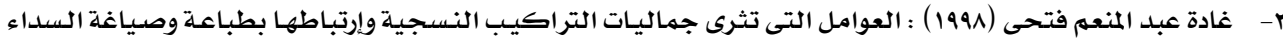

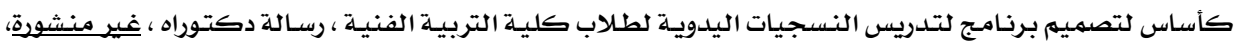

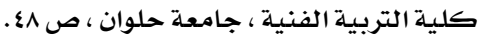




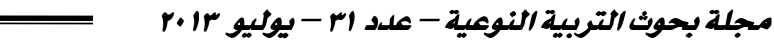

واحسـ يختلف المظهر السطحى للمنسسوجات عمـا إذا كانت شـرائط السلداء بلـون مخـالف لشرائط

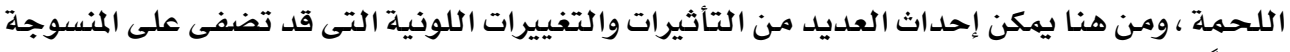

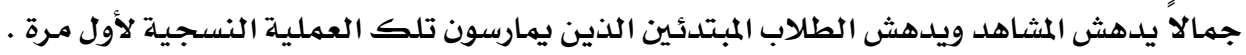
ومـن أهـم مميـزات إسـتخدام الشرائط الجـاهزة إنها تظهـر بدرجـة كبيرة بعـد إتهـام عمليـة

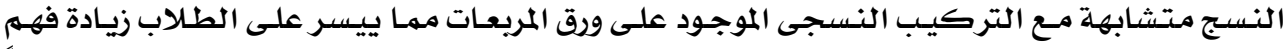

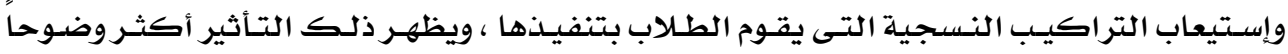

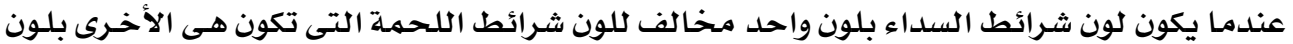

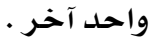

فالتجريب بإستخدام الخامـة وهى الشرائط الجاهزة كبديل للخيوط فى هذا البحث كان

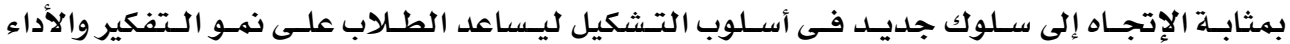

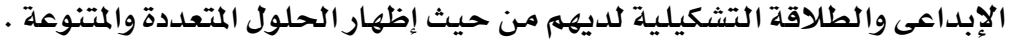

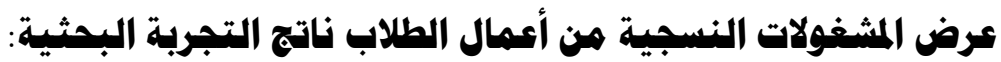
المشفولة النسجية الأولى - الى

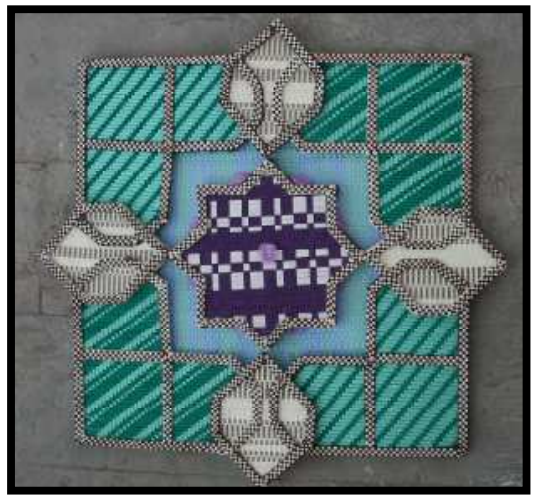

الشفولة النسجية الثانية

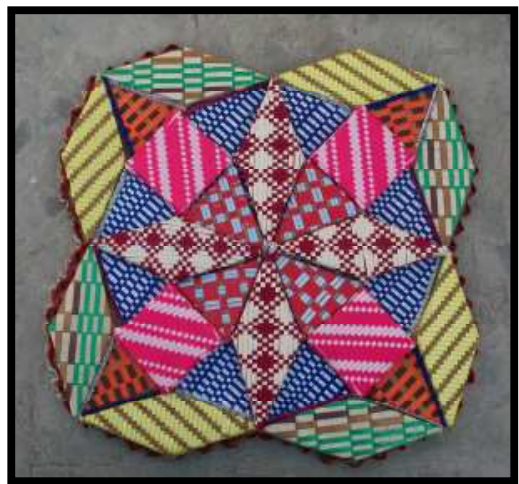


المشفولة النسجية الثالثة

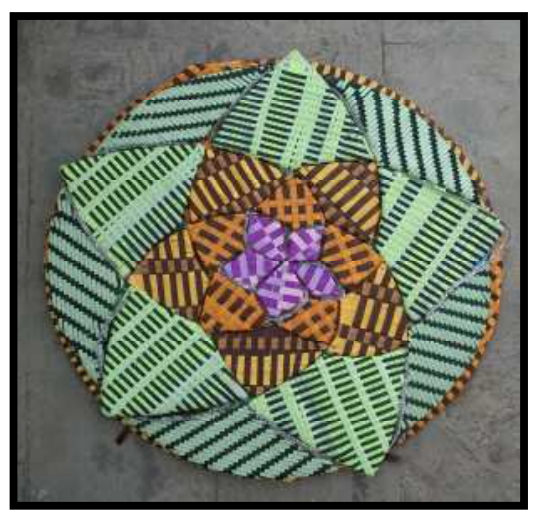

المشفولة النسجية الرابعة

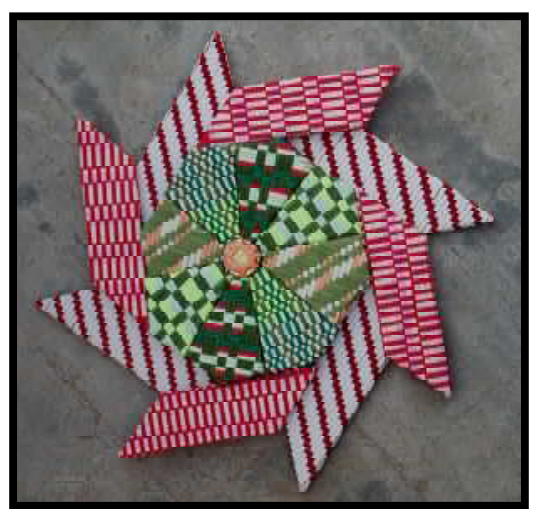

المشفولة النسجية الخامسة

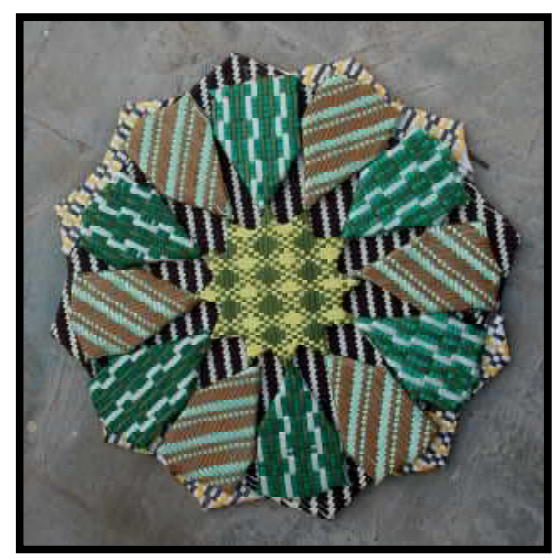




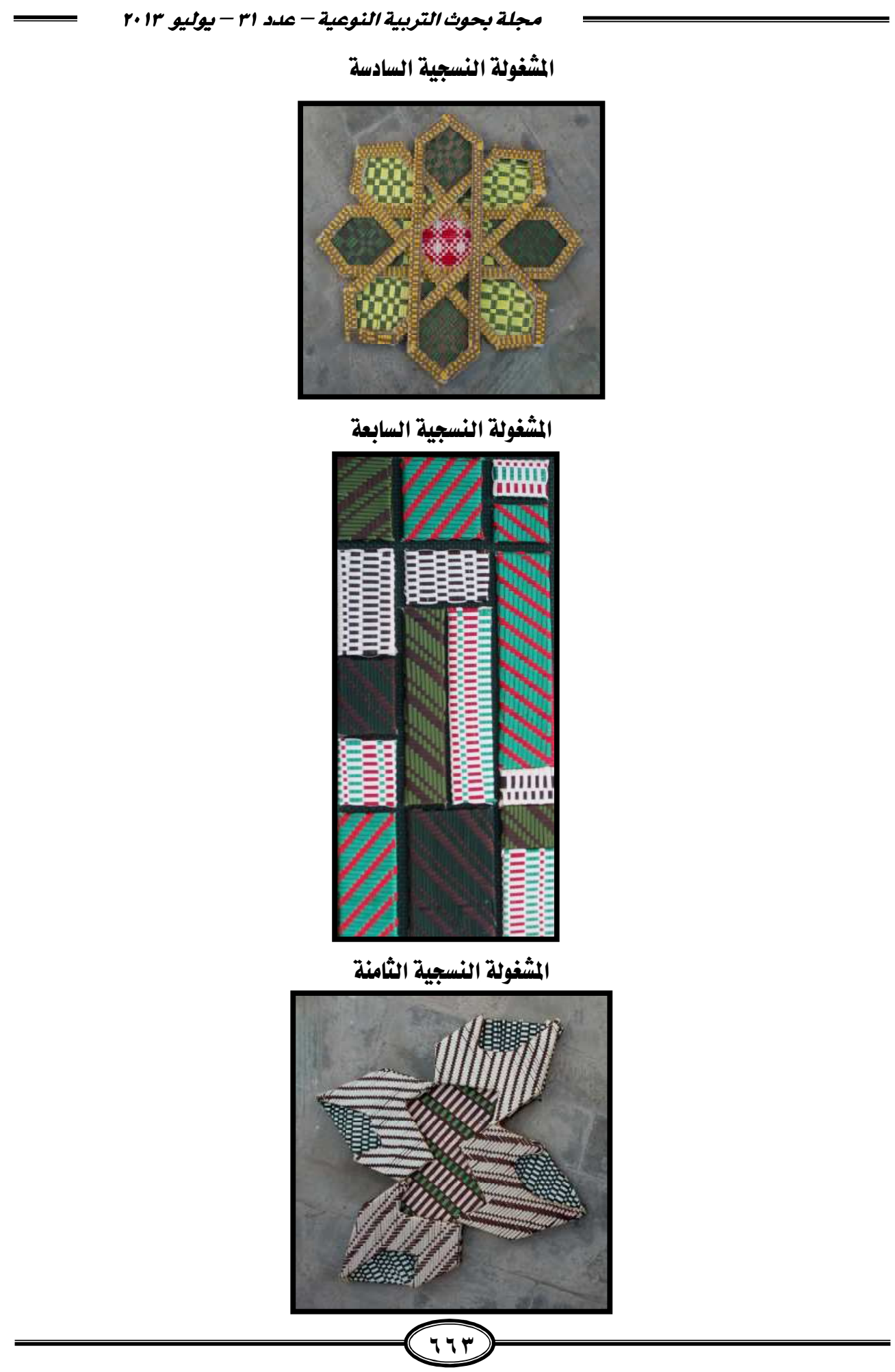


المشفولة النسجية التاسعة

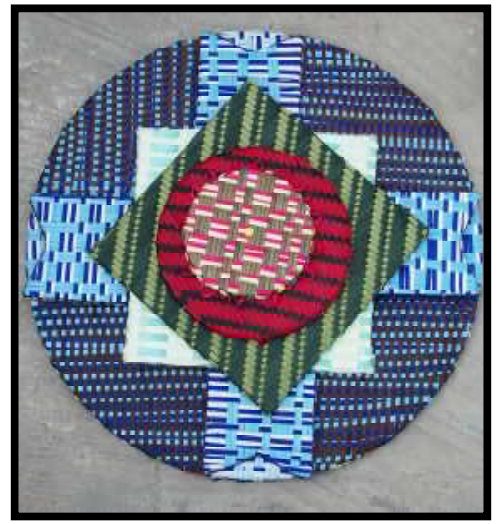

المشفولة النسجية العاشرة

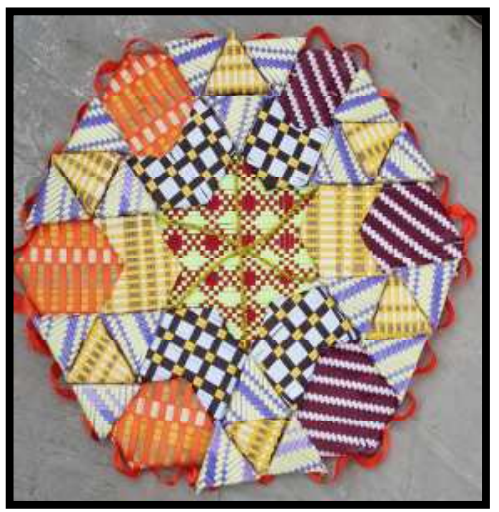

المشفولة النسجية الحادية عشر

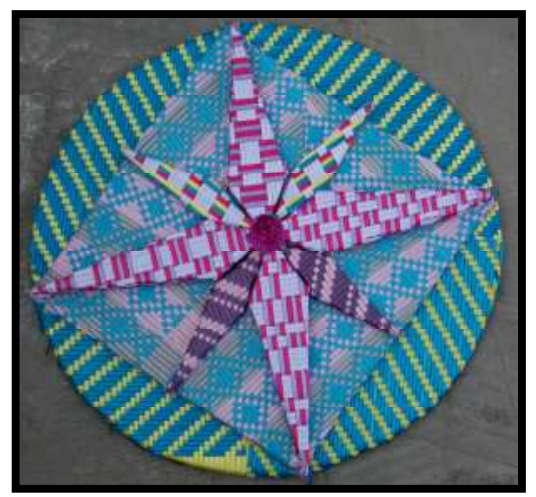




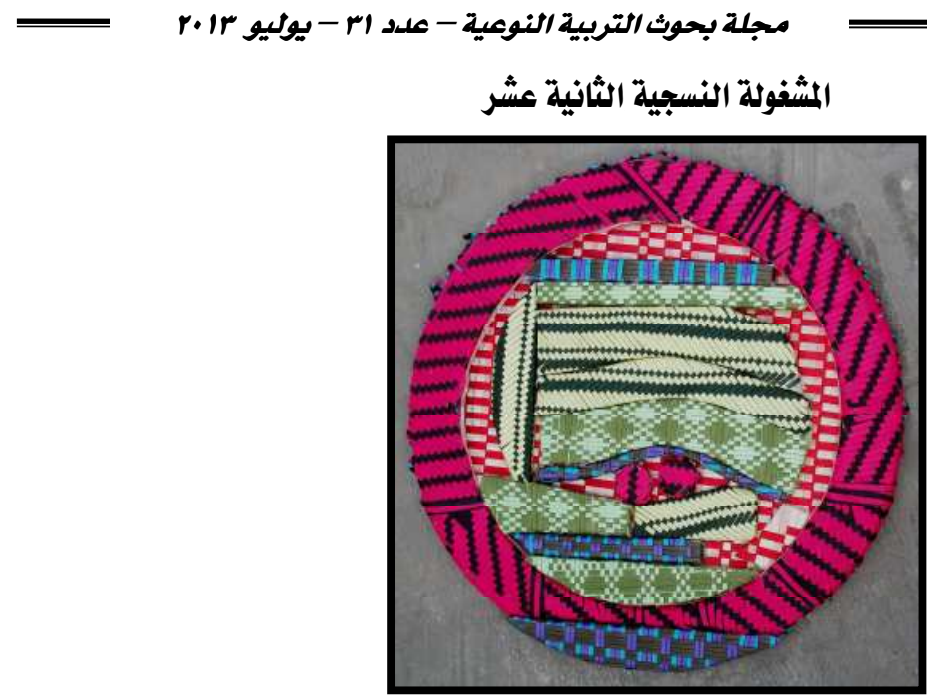

الشفولة النسجية الثالثة عشر

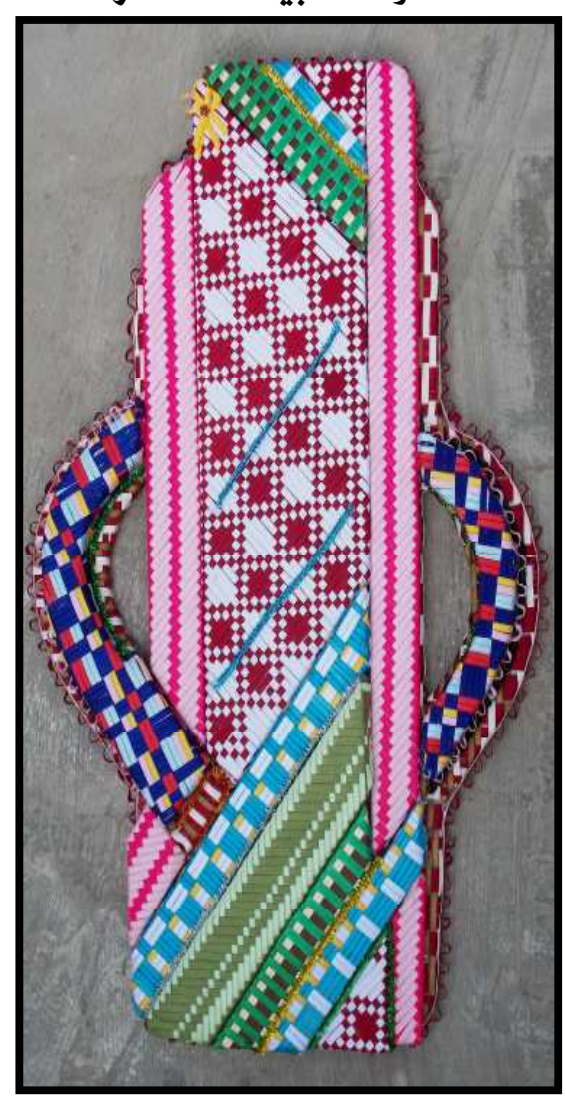


الشفولة النسجية الرابعة عشر
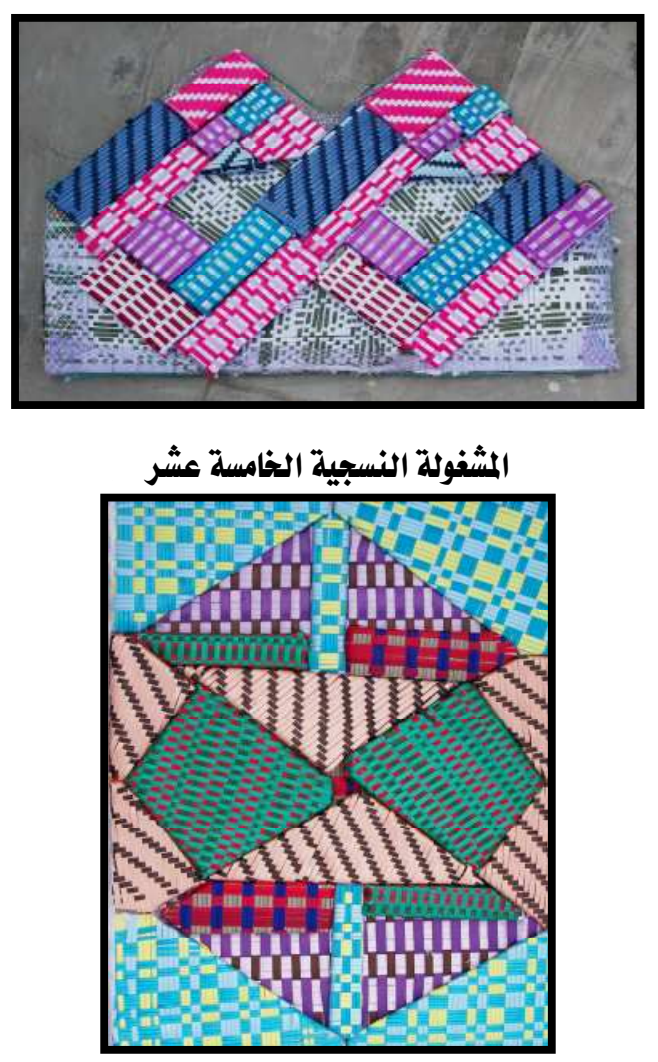

الشفولة النسجية السادسة عشر

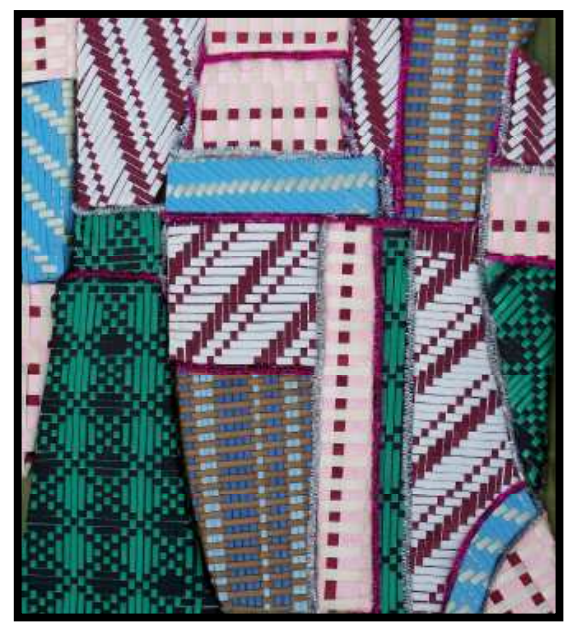


المشفولة النسجية السابعة عشر

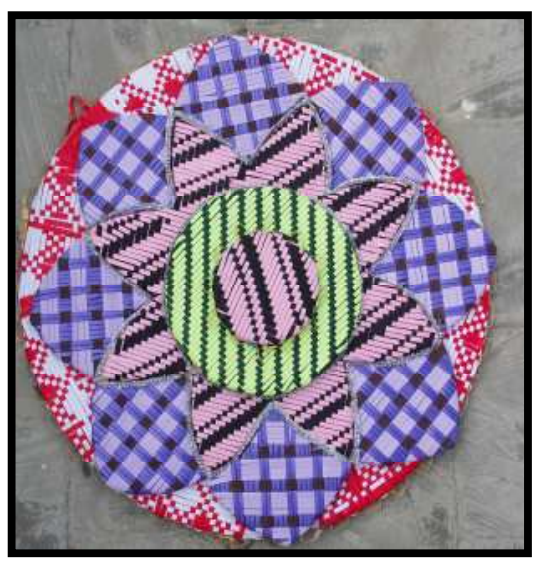

المشفولة النسجية الثامنة عشر

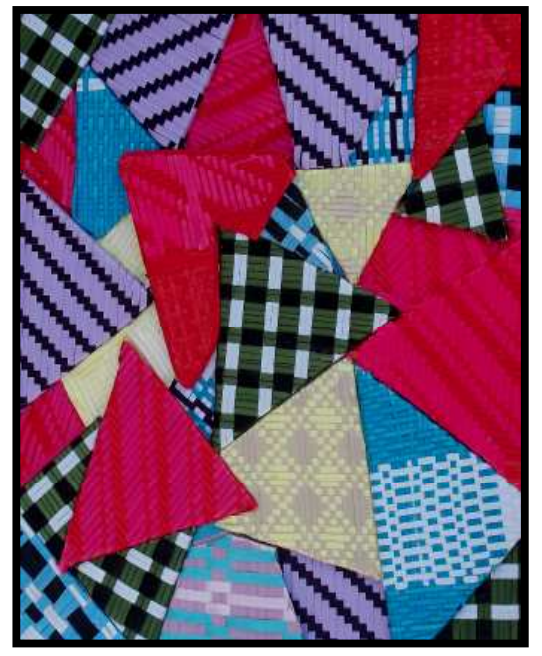

نتائج البمث :

من خلال الدراسة النظريـة والتجرية العملية أمكن التوصل إلى النتائج الآتية:

• يمكن استخدام الأشرطة الجاهزة ذو العروض المختلفة ِِّ تنفيذ المشغولات النسجية.

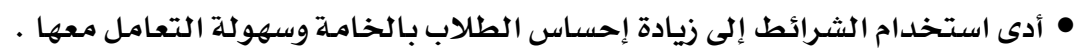

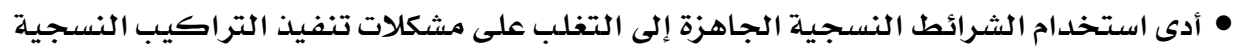
للمبتدئين .

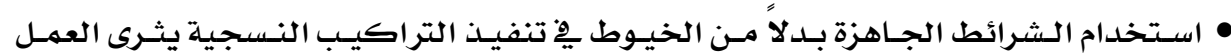
النسجي للطلاب المبتدئين النشئ 
1- أسماء محمد خطاب : تنمية القدرة على التفكير الإبتكارى باستخدام الحاسب الآلي يِّ مجـال النسجيات

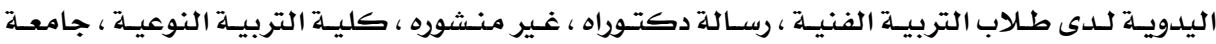

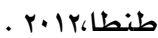

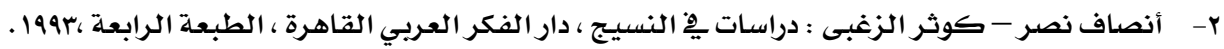

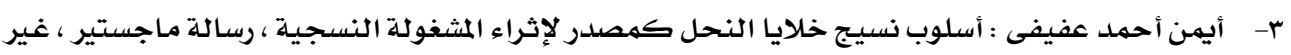

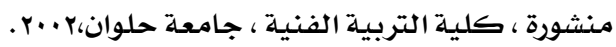

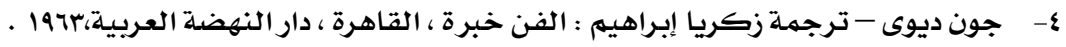

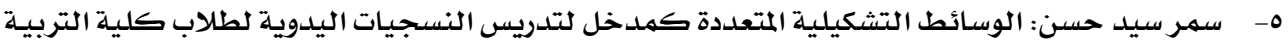

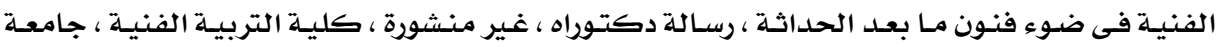

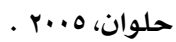

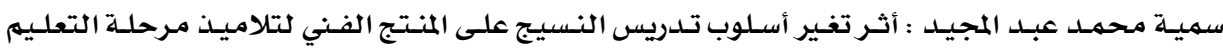
الأساسى ، رسالة دكتوراه ، غير منشوره ، كلية التربية الفنية ، جامعة حلوان ،1991.

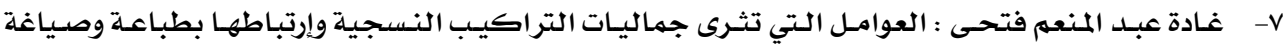

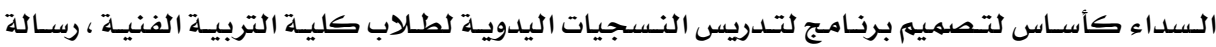

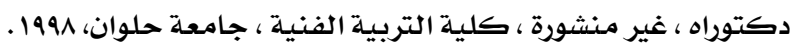

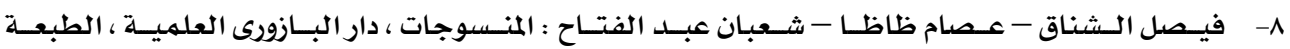

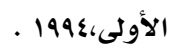
9- محمد أبو القاسم : الخامة كعنصر إلهام وتوجيه الفنـان ، علوم وفنـون ، دراسـات وبحوث - العـدد الرابـع ،

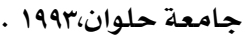

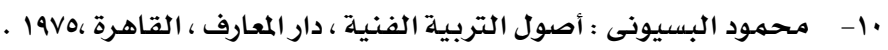

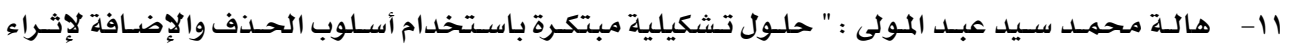
المشغولة النسجية "، رسالة ماجستير ، غير منشورة ، كلية التربية الفنية ، جامعة حلوان ، ع ..ب.

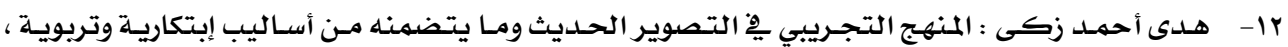

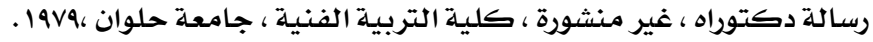

